\title{
AOR
}

Selected Papers of \#AolR2019: The $20^{\text {th }}$ Annual Conference of the Association of Internet Researchers Brisbane, Australia / 2-5 October 2019

\section{LEVERAGING TRUST: YOUTUBE ENTERTAINERS AND THE ROLE OF PROBLEM-SOLVING IN ENGENDERING TRUST}

\author{
Guy Hamilton Healy \\ QUT
}

\begin{abstract}
Negative accounts of YouTube creators can dominate mainstream media
Dominant accounts of social media entertainers emphasise their roles as microcelebrities and influencers, with some of these accounts focusing on the negative, especially their performance of dangerous and often 'idiotic' stunts as part of their audience-building and sustainability (Goriunova, 2012), for example the Bird Box and Tide Pod challenges. Indeed a spike in YouTubers 'doing dangerous shit for views' (Weisenstein, 2019), part of the longstanding phenomenon inspired by television show Jackass, (Lange, 2007), belatedly forced the platform to ban such videos earlier this year. But this paper suggests that any such stereotype of widespread thoughtless creators is misplaced, and instead, leading creators are doing problem-solving that is highly valued by their fan communities, who creators report can also be thoughtful and co-creative. As quoted in Turner (2012), Microsoft Research senior researcher danah boyd has observed, 'the internet mirrors and magnifies the good and the bad and the ugly.
\end{abstract}

\section{Authenticity interrogated through lens of problem-solving}

This paper asks how important is the role of trust in audience-development and thus creator sustainability, and to what extent, if any, does trust building by creators involve a formal strategy of problem-solving to better engage fans? Trust in this context is that between creators and their fan communities, where trust is defined as 'a form of belief in the reliability, truth or ability of someone or something'. Cunningham \& Craig (2017) argue the fundamental appeal of YouTubers is expressed through discursive appeals to authenticity and community, but this paper interrogates those appeals through the lens of whether problem-solving around fans' key life problems engenders trust.

\section{Evolution of "harnessing the hive"}

Over the past decade, scholars have increasingly focused on the potential of Web 2.0 technologies to enable collaborative problem-solving by 'harnessing the hive' (Bruns, 2008), and the tremendous agency of small numbers of highly talented young people to adapt software and protocols to serve their own needs and desires (Lindgren, 2011). A significant focus of these studies has been the use of web-based collaborative tools 
to simulate global workplaces (Andone \& Frydenberg, 2014), and better engage young teenage learners via 'problem-solving videos' (Richards-Babb, el al, 2014).

\section{Lifeworld's of creators and by extension, fans, revealed}

The paper adopts a mixed methods approach - in this case in-depth interviews, discourse analysis and observation at YouTube Creator Day events - to better leverage the strengths of each method, and provide triangulation of results (Onwuegbuzie \& Leech, 2006). Sample size for interviews is 20 among YouTubers with an average of at least $1 \mathrm{mn}$ subscribers, at the most culturally significant, even artistic end of the spectrum, established TV producers and Multi-Channel Network leaders. Participant observation was also conducted at over half a dozen official YouTube Creator Days since 2016, as well as VidCon Melbourne 2017.

\section{Problem-solving by progressive creators needs to be better understood}

This research speaks directly to at least three of the specific themes of \#AoIR2019: firstly, trust in our fellow Internet users; second, trust in the information we encounter in our online environments; and third, trust in those who create the digital content we consume. The research is significant for three reasons: first, these creators represent contemporaneous cultural power: YouTube itself attributes the 'originality and hard work' of creators with a new milestone: $1 \mathrm{bn}$ hours of YouTube watched globally, daily (Goodrow, 2017); second, these creators offer the opportunity to better understand an important cultural counterweight to abusive Internet users who use Facebook, Twitter and indeed YouTube to disseminate hate via 'platformed racism' (MatamorosFernandez, 2017). Third, the rise of interactive fan communities centred around and built up by social media entertainers (Cunningham \& Craig, 2019), arguably represents a significant shift in the agency of creators and their co-creative fans, especially their mutual ability to independently articulate their problems and determine solutions collectively. As Svedmark (2016) acknowledges, the world confronts 'big questions regarding the environment, overpopulation, migration and starvation', and in the context of the post-human, better understanding knowledge production on social media platforms that promotes 'informed choices' is more needed than ever.

\section{Problem-solving used to build trust, sustainable livings}

This research is in progress, however preliminary findings suggest that problemsolving is used to build trust, which is in turn leveraged for creator sustainability. For example, Joey Graceffa has reported that seeing another YouTuber 'openly talking about her issues with her mom', was the inspiration for understanding that he did not have anyone growing up that he could relate to, so motivating his YouTube career (Graceffa, 2015). Similarly, Hank Green of vlogbrothers, has reported that their Crash Course and SciShow channels were motivated by the idea of 'performing a broader social good' (Green, 2015). This work suggests that this strategy of problem-solving is so effective at trust and audience-building for two main reasons: first, it is founded in the consistent, persistent labour-intensive work by creators of interacting with fans in the comment streams of their multi-platform small businesses; second, this labour is characterised by being co-creative with fans, thus affording creators a rich set of insights into the lifeworld's of their fan communities, and often resulting in fan feedback-enhanced video products, and, in turn new fan 'reaction' videos.

\section{Creators able to articulate problems, and solutions}


Artistically creative individuals are known not just for their ability to solve problems, but for their ability to articulate "new problems and formulate these in ways that could lead to a solution' (Livingstone, 2009; Csikszentmihalyi, 2014). Moreover, creativity needs to be approached less from first-generation thinking that regards creativity as a mysterious, serendipitous property possessed by gifted individuals, and more as a second-generation creativity that optimises 'the capacity and potential of potentially everyone' (Cunningham, 2011).

In conclusion, this Web 2.0-enabled nexus between creators and fans is likely to be highly generative as regards problem-solving, now and into the future, and needs to be better understood.

Andone, D., \& Frydenberg, M. (2014). Becoming Creative Creators: Simulating a Global Workplace using Computational Thinking Practices. In EdMedia+ Innovate Learning (pp. 564-571). Association for the Advancement of Computing in Education (AACE).

Bruns, A. (2008). The future is user-led: The path towards widespread produsage. Fibreculture journal, (11).

Csikszentmihalyi, M. (2014). The systems model of creativity: The collected works of Mihaly Csikszentmihalyi. Springer.

Cunningham, Stuart D. (2011) Can creativity be taught? And why should it be? In Wright, Shelagh, Kieffer, John, Holden, John, \& Newbigin, John (Eds.) Creativity, Money, Love: Learning for the 21st Century. Creative Blueprint.

Cunningham, S., \& Craig, D. (2017). Being 'really real'on YouTube: authenticity, community and brand culture in social media entertainment. Media International Australia, 164(1), 71-81.

Cunningham \& Craig (2019) Social Media Entertainment: The New Intersection of Hollywood and Silicon Valley. NYU Press.

Goodrow. C., (2017). You know what's cool? A billion hours. Google, California, Mountain View. Retrieved from:

https://youtube.googleblog.com/2017/02/you-know-whats-cool-billion-hours.html

Goriunova, O. (2013). New media idiocy. Convergence, 19(2), 223-235. 
Graceffa, J. (2015) Creator (JoeyGraceffa), 06 July, interview with David Craig, United States In Cunningham \& Craig (2019) Social Media Entertainment: The New Intersection of Hollywood and Silicon Valley. NYU Press.

Green, H. (2015). Creator (VlogBrothers), 05 July, interview with David Craig, United States In Cunningham \& Craig (2019) Social Media Entertainment: The New Intersection of Hollywood and Silicon Valley. NYU Press.

Lange, P. G. (2007). Fostering friendship through video production: How youth use YouTube to enrich local interaction. In Annual Meeting of the International Communication Association (Vol. 27).

Lindgren, S. (2011). Collective problem-solving and informal learning in networked publics: Reading vlogging networks on YouTube as knowledge communities. In Interactive Media Use and Youth: Learning, Knowledge Exchange and Behavior (pp. 50-64). IGI Global.

Livingston, P. (2009). Poincaré's" Delicate Sieve": on creativity and constraints in the arts. Digital Commons @ Lingnan University. Retrieved from: https://commons.In.edu.hk/philo_sw/3/

Matamoros-Fernandez, A. (2017). Platformed racism: The mediation and circulation of an Australian race-based controversy on Twitter, Facebook and YouTube. Information, Communication \& Society, 20(6), 930-946.

Onwuegbuzie, A. J., \& Leech, N. L. (2006). Linking research questions to mixed methods data analysis procedures 1 . The qualitative report, 11(3), 474-498.

Richards-Babb, M., Curtis, R., Smith, V. J., \& Xu, M. (2014). Problem solving videos for general chemistry review: Students' perceptions and use patterns. Journal of Chemical Education, 91(11), 1796-1803.

Turner, F. (2012). A Conversation with danah boyd, Microsoft Research. Television \& New Media, 13(2), 177-185.

Weisenstein, K. (2019). How YouTube's ban on Dangerous Stunts Will Affect Creators. Vice News. Retrieved from: https://www.vice.com/en_au/article/9k4epy/how-youtubes-ban-on-dangerous-stuntswill-affect-creators 